\title{
Tissue differential expression of lycopene $\beta$-cyclase gene in papaya
}

\author{
Rachel L Skelton ${ }^{1}$, Qingyi Yu ${ }^{1}$, Rajeswari Srinivasan ${ }^{2}$, Richard Manshardt ${ }^{2}$, Paul H Moore ${ }^{3}$, Ray Ming ${ }^{1,4}$ \\ ${ }^{1}$ Hawaii Agriculture Research Center, Aiea, HI 96701, USA; ${ }^{2}$ Department of Tropical Plant and Soil Sciences, University of Hawaii, \\ Honolulu, HI 96822, USA; ${ }^{3}$ USDA-ARS, Pacific Basin Agricultural Research Center, Aiea, HI 96701, USA; ${ }^{4}$ Department of Plant \\ Biology, University of Illinois at Urbana-Champaign, Urbana, IL 61801, USA
}

Carotene pigments in flowers and fruits are distinct features related to fitness advantages such as attracting insects for pollination and birds for seed dispersal. In papaya, the flesh color of the fruit is considered a quality trait that correlates with nutritional value and is linked to shelf-life of the fruit. To elucidate the carotenoid biosynthesis pathway in papaya, we took a candidate gene approach to clone the lycopene $\beta$-cyclase gene, $L C Y-B$. A papaya $L C Y-B$ ortholog, $c p L C Y-B$, was successfully identified from both cDNA and bacterial artificial chromosome (BAC) libraries and complete genomic sequence was obtained from the positive BAC including the promoter region. This $c p L C Y-B$ shared $80 \%$ amino acid identity with citrus $L C Y-B$. However, full genomic sequences from both yellow- and red-fleshed papaya were identical. Quantitative real-time PCR (qPCR) revealed similar levels of expression at six different maturing stages of fruits for both yellow- and red-fleshed genotypes. Further expression analyses of $c p L C Y-B$ showed that its expression levels were seven- and three-fold higher in leaves and, respectively, flowers than in fruits, suggesting that $c p L C Y$ - $B$ is down-regulated during the fruit ripening process.

Cell Research (2006) 16:731-739. doi:10.1038/sj.cr.7310081; published online 27 June 2006

Keywords: Carica papaya, fruit flesh color, lycopene $\beta$-cyclase

\section{Introduction}

Papaya (Carica papaya L.) is a productive fruit crop cultivated in tropical and sub-tropical regions worldwide. The consumed fruit, rich in vitamins $\mathrm{A}$ and $\mathrm{C}$, has been recommended for the prevention of vitamin A deficiency in some countries [1,2]. Two flesh colors, yellow and red, of papaya fruit are controlled by a single gene with yellow color as dominant $[3,4]$. It has been previously documented that yellow-fleshed fruits have high amounts of the carotenoid $\beta$-cryptoxanthin and $\zeta$-carotene but lack lycopene, whereas red-fleshed fruits have high amounts of lycopene along with $\beta$-cryptoxanthin, $\beta$-carotene, and $\zeta$-carotene $[2$, $5,6]$. The red color of papaya fruit is due to the accumulation of lycopene; the yellow color is the result of converting

\footnotetext{
Correspondence: Ray Ming

Fax: +1-217-244-1336;

E-mail: rming@life.uiuc.edu

Received 1 Feb 2006; revised 24 Feb 2006; accepted 27 Mar 2006; published online 27 Jun 2006
}

lycopene to $\beta$-carotene and $\beta$-cryptoxanthin [6-8].

Pigments such as lycopene and $\beta$-carotene are fat-soluble carotenoids essential to all higher plant species. Lycopene gives many red-fleshed fruits their brilliant color [9] and is found in the chloroplasts and chromoplasts of tomatoes, watermelon, guava, pink grapefruit, and papaya [10]. Owing to lycopene storage in tight protein-carotenoid complexes, cooking and processing actually makes it more available in animal diets [11]. Lycopene is a direct precursor of $\beta$ carotene, one of the most active and essential carotenoids. Conversion of lycopene to $\beta$-carotene is catalyzed by lycopene $\beta$-cyclase $(L C Y-B)$, as described below. Accumulation of lycopene during fruit ripening is due to down-regulation of the $L C Y-B$ gene activity [12].

Carotenoid pigments in the chloroplast of green tissues function to block the high-light lethal effects of oxygen and free radicals resulting from the transfer of electrons from triplet chlorophyll to molecular oxygen [12-14]. Carotenoid pigments are synthesized in the isoprenoid biosynthetic pathway within the chloroplasts of algae and plants. Lycopene is formed from four desaturation or dehydrogenation 
reactions that begin with phytoene [15]. Two further steps in the pathway result in the conversion of red lycopene to yellow cryptoxanthin, first converting lycopene to $\beta$ carotene by $L C Y-B$ and then to $\beta$-cryptoxanthin by $\beta$-ring hydroxylase [16-20].

Two cyclases, encoded by single genes in Arabidopsis, work within the carotenoid biosynthetic pathway to convert the linear lycopene structure to other carotenoids by the addition of rings on the end of the molecule [18]. $L C Y-B$ adds a $\beta$-ring to each end of the lycopene molecule, resulting in the production of the yellow $\beta$-carotene. With the addition of one $\varepsilon$-ring to lycopene, lycopene $\varepsilon$-cyclase creates $\delta$-carotene, which then is converted to $\alpha$-carotene through a single $\beta$-ring addition catalyzed by $L C Y$ - $B$ (Figure 1) $[16,18-20,21,22]$. It is through this pathway that one carotenoid is converted to another, giving the fruit its specific flesh color.

While all plants have lycopene $\varepsilon$ - and $\beta$-cyclases, some plants have additional cyclases. In capsicum peppers, the enzyme capsanthin-capsorubin synthase $(C C S)$ converts violoxanthin and antheraxanthin to capsanthin and capsorubin, which give red color to the fruits. In addition, $C C S$ also has some $L C Y-B$ activity $[12,18,24,25]$. In tomato, a second lycopene $\beta$-cyclase specific to the chromoplast has been identified [26] and named $C Y C-B$ [8]. $C Y C-B$, which is homologous to pepper $C C S(86.1 \%)$, produces $\beta$-carotene in tomato fruits [27]. Another enzyme in the carotenoid pathway, neoxanthin synthase (NXS), shows $98 \%$ sequence homology to $C Y C-B$, in tomato [27]. Function, gene sequences, and map position suggest that $C C S$ and $C Y C-B$ are orthologs arising from $L C Y-B$ by gene duplication [8].

Kapoho and SunUp are parental cultivars of the hybrid Rainbow that accounts for majority of the papaya fruit produced in Hawaii. Kapoho is a popular commercial cultivar that is pear-shaped with a short neck and yellow flesh. SunUp is a transgenic red-fleshed cultivar that was developed to be resistant to papaya ringspot virus [28].

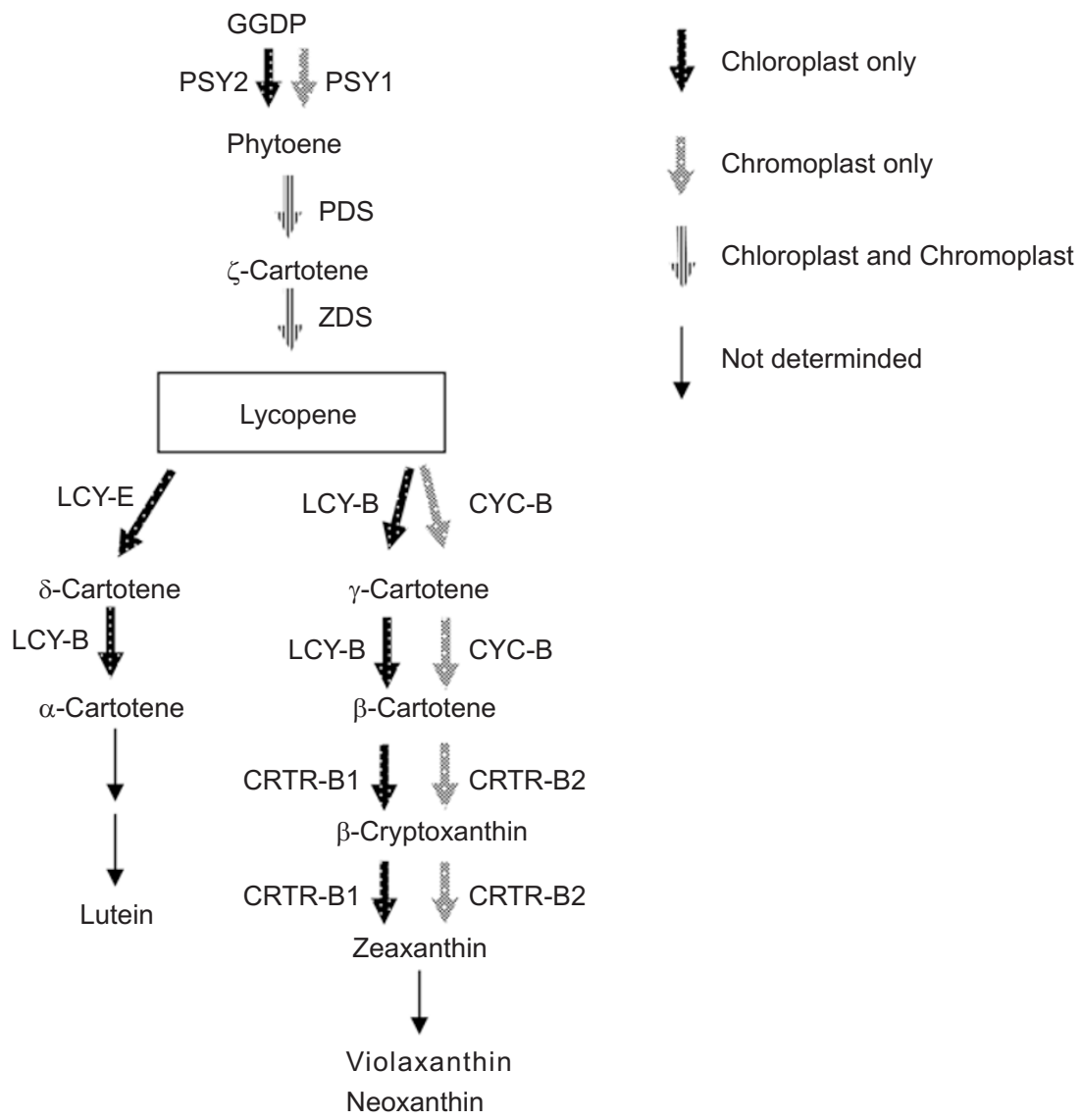

Figure 1 Pathway of carotenoid biosynthesis in plants $[8,22,23,26]$. PSY, phytoene synthase; PDS, phytoene desaturase; ZDS, $\zeta$-carotene desaturase; LCY-B, lycopene $\beta$-cyclase; LCY-E, lycopene $\varepsilon$-cyclase; CYC-B, chromoplast-specific lycopene $\beta$-cyclase; and CRTR-B, $\beta$-ring hydroxylase. 
SunUp was developed from the original red-fleshed papaya, Sunset, and is homozygous for the coat protein gene. Both SunUp and Kapoho play key roles in the papaya industry as commercial cultivars and as parents of the transgenic hybrid cultivar Rainbow.

Based on previous reports, lycopene appeared to be the determining factor in the red color of papaya flesh. The objectives of this project were to clone the $L C Y$ - $B$ gene in papaya and to test its expression pattern in yellow and red papaya cultivars.

\section{Materials and Methods}

\section{Plant materials}

Young leaf tissues of SunUp and Kapoho were collected from Kunia Station, Oahu for isolating genomic DNA. Fruits of these two cultivars were collected at three fruit size expansion and three fruit ripening stages (color break, $30 \%$, and $90 \%$ ripe) for isolating RNA to test the levels of target gene expression.

\section{DNA isolation}

Bacterial artificial chromosome (BAC) DNA was isolated from the papaya BAC library [29] using Qiagen REAL kits (Qiagen, Valencia, CA, USA). Genomic DNA was isolated from young leaf tissues using a method described previously with minor modifications [30]. Concentrations of the isolated DNA were checked on $0.9 \%$ agarose gels, displaying an average DNA concentration of $30 \mathrm{ng} / \mu \mathrm{l}$.

\section{Designing degenerate primers}

cDNA sequences of lycopene $\beta$-cyclase of navel orange, grapefruit, Capsicum, tomato, tobacco, Adonis, marigold, and Arabidopsis were obtained using the Basic Local Alignment Search Tool (BLAST) available at National Center for Biotechnology Information (NCBI). All $L C Y-B$ sequences were aligned using the software Seqweb (Accelrys Inc., San Diego, CA, USA) to produce a consensus sequence. A 29-bp forward-degenerate primer and 22-bp reverse-degenerate primer were designed. The primers were checked for dimer and hairpin formation using the software Oligoanalyzer 3.0 from Integrated DNA Technologies Inc. (Coralville, IA, USA). A polymerase chain reaction (PCR) consisting of 35 cycles of denaturation at $90{ }^{\circ} \mathrm{C}$, annealing at $50{ }^{\circ} \mathrm{C}$, and elongation at $72{ }^{\circ} \mathrm{C}$ was carried out using genomic DNA from papaya cultivar SunUp.

In a similar manner, degenerate primers were designed for a consensus sequence obtained from cDNA sequences of $C Y C-B$ gene from tomato, CCS gene from Capsicum, and navel orange and NXS from tomato and potato, to clone a $C Y C-B$ gene in papaya. As this $C Y C-B$ gene from tomato also does not have any intron [26], genomic DNA from papaya cultivar SunUp was used. Amplification was done with tomato DNA as a control. Annealing temperatures ranging from $50-54{ }^{\circ} \mathrm{C}$ were tried.

\section{Superpool and matrix pool construction}

Matrix technology (Amplicon Express, Pullman, WA, USA) was utilized to allow location identification of specific BAC clones within the 102 384-well plates in our BAC library. A total of nine superpools (SP1-9), eight (SP1-8) containing 12 384-well plates, and one (SP9) containing six 384-well plates were assigned to cover the entire library. Each superpool contains 4608 individual clones and the entire BAC library covers $13.7 \times$ haploid-genome equivalents [29]. Each individual superpool was then organized into matrix pools, positioning the clones in a matrix of plate, row, column, and diagonal pools. This matrix setup ensures that each of the clones is represented in two of the matrix pools.

Round I PCR was then performed on all of the superpools, screening the entire BAC library. The reaction was carried out in $24 \mu \mathrm{l}$ volume consisting of approximately $30 \mathrm{ng} / \mu 1$ of the template DNA, $0.2 \mathrm{mM}$ dNTPs, $1 \times$ PCR buffer, $1.5 \mathrm{mM} \mathrm{MgCl}_{2}$ and $2 \mathrm{UI}$ of Taq polymerase (Promega, Madison, WI, USA). The PCR reaction consisted of denaturation for $3 \mathrm{~min}$ at $94{ }^{\circ} \mathrm{C}$ and then 35 cycles of denaturation for $30 \mathrm{~s}$ at $94{ }^{\circ} \mathrm{C}$, annealing for $45 \mathrm{~s}$ at $55^{\circ} \mathrm{C}$, and elongation for 1 min at $72{ }^{\circ} \mathrm{C}$, followed by an extension time of $7 \mathrm{~min}$ at $72{ }^{\circ} \mathrm{C}$. The positive PCR results from Round I then underwent Round II PCR, which was performed on the matrix pools (plate, row, column, and diagonal pools) of each superpool. A third, confirmation PCR reaction was used to identify the source plates within our BAC library that contained the desired clone. All PCR confirmation was determined by running the PCR product on $0.9 \%$ agarose gel.

\section{Southern hybridization}

Concurrent with the BAC library screening using the superpool technology, both the BAC library and cDNA library of the papaya hermaphrodite and female flowers were screened for positive BACs by Southern hybridization as described previously [29].

\section{Individual BAC clone isolation and PCR confirmation}

BAC stocks were streaked onto LB agar plates containing chloramphenicol. The single colonies were inoculated and grown in LB liquid medium containing chloramphenicol. The individual BAC DNA was isolated using Qiagen Midiprep (Qiagen, Valencia, CA, USA). The positive BAC clones were confirmed by a PCR reaction consisting of a 3 min denaturation at $94{ }^{\circ} \mathrm{C}$ and then 35 cycles of denaturation at $94{ }^{\circ} \mathrm{C} 30 \mathrm{~s}$, annealing at $55^{\circ} \mathrm{C}$ for $45 \mathrm{~s}$, and elongation at $72{ }^{\circ} \mathrm{C}$ for $1 \mathrm{~min}$, followed by an extension time at $72{ }^{\circ} \mathrm{C}$ for $7 \mathrm{~min}$. The reaction was carried out in $24 \mu \mathrm{l}$ volume consisting of either $20 \mathrm{ng} / \mu 1$ or $40 \mathrm{ng} / \mu$ lof the template DNA, $0.2 \mathrm{mM}$ dNTPs, $1 \times$ PCR buffer, $1.5 \mathrm{mM} \mathrm{MgCl} \mathrm{M}_{2}$ and $2 \mathrm{U}$ of Taq polymerase (Promega, Madison, WI, USA).

\section{DNA sequencing}

Direct sequencing of the positive BAC DNA was started with primers TIGR994C and TIGR994D (GeneBank Accession No. CG026994). Further sequencing of the upstream and downstream regions was conducted by primer walking. After each sequencing result was obtained, a new primer was designed to allow further reading of both upstream and downstream regions.

Sequencing was done using the ABI 3700 Analyzer and the Big Dye Terminator Sequencing kit (Applied Biosystems, Foster City, CA, USA). The sequencing reaction consisted of $1 \mathrm{~min}$ of $96^{\circ} \mathrm{C}$ denaturation and then 25 cycles of denaturation at $96^{\circ} \mathrm{C}$ for $10 \mathrm{~s}$, annealing at $50{ }^{\circ} \mathrm{C}$ for $5 \mathrm{~s}$, and extension at $60{ }^{\circ} \mathrm{C}$ for $4 \mathrm{~min}$. The sequencing reaction was carried out in a $20 \mu \mathrm{l}$ volume consisting of $1.4 \mu \mathrm{g}$ of template DNA, $4 \mu \mathrm{M}$ primer, $1 / 16 \times$ Big Dye Reaction Premix, $5 \times$ Sequencing Buffer (Applied Biosystems), and water.

\section{RNA isolation and preparation}

Total RNA was isolated from SunUp and Kapoho fruits of three size expansion and three ripening stages of $5 \%, 30 \%$, and $90 \%$ 
Table 1 Degenerate primers designed from multiple $L C Y-B$ and $C Y C-B$ sequences of diverse plant species

\begin{tabular}{ll}
\hline Primers & Sequences \\
\hline$L C Y-B$ and $C Y C$ - $B$ Forward & 5'-AAY TAT GGW GTT TGG GTD GAT GAR TTT GA-3' \\
$L C Y-B$ Reverse & 5'-TAD GGY TTR TCA TAY TGV ACH A-3' \\
$C Y C$ - $B$ Reverse & 5'-GGC TCA TTM CCY AAA TGR G-3' \\
\hline $\mathrm{Y}=\mathrm{C}$ - $; \mathrm{W}=\mathrm{A} \cdot \mathrm{T} ; \mathrm{D}=\mathrm{A}, \mathrm{G}, \mathrm{T} ; \mathrm{R}=\mathrm{A}, \mathrm{G} ; \mathrm{V}=\mathrm{A}, \mathrm{C}, \mathrm{G} ; \mathrm{H}=\mathrm{A} C$, and $\mathrm{M}=\mathrm{A} C \mathrm{C}$
\end{tabular}

$\mathrm{Y}=\mathrm{C}, \mathrm{T} ; \mathrm{W}=\mathrm{A}, \mathrm{T} ; \mathrm{D}=\mathrm{A}, \mathrm{G}, \mathrm{T} ; \mathrm{R}=\mathrm{A}, \mathrm{G} ; \mathrm{V}=\mathrm{A}, \mathrm{C}, \mathrm{G} ; \mathrm{H}=\mathrm{A}, \mathrm{C}$, and $\mathrm{M}=\mathrm{A}, \mathrm{C}$.

yellowing using hot phenol extraction. RNA was then treated with RNase-free RQ1 DNase I for $30 \mathrm{~min}$ at $37^{\circ} \mathrm{C}$ to eliminate potential genomic contamination, the RQ1 DNase Stop Solution was added, and the mixture was incubated for another $10 \mathrm{~min}$ at $65^{\circ} \mathrm{C}$ (Promega, Madison, WI, USA). Total RNA concentration was measured on a $37 \%$ formaldehyde DNase-RNase free gel.

\section{Quantitiative real-time PCR ( $q P C R)$}

To assess lycopene $\beta$-cyclase expression at different organs and six fruit developmental stages of SunUp and Kapoho, qPCR was performed on the $5 \times$ diluted $\mathrm{RT}$ reaction using reagents from Applied Biosystems (Foster City, CA, USA) and primers designed from the SunUp papaya lycopene sequence (forward, 5' ACT TGC TAG ACT GCC TTG AC; reverse 5' ACA GTG GCC TGA ATC GTA AC). Papaya actin was included as the positive control. PCR was performed in a $50 \mu \mathrm{l}$ reaction using a master mix containing $25 \mu 1$ Platinum SYBR Green qPCR Supermix-UDG, $1 \mu$ l RXX reference dye, and $13 \mu \mathrm{l}$ water. Eight microliters of the diluted RT reaction, $3 \mu \mathrm{l}$ of $5 \mu \mathrm{M}$ primer, and $39 \mu \mathrm{l}$ master mix were combined and run on an Opticon2 Continuous Fluorescence Detection System (MJ Research, Waltham, MA, USA). The PCR program was as follows: $50{ }^{\circ} \mathrm{C}$ for $2 \mathrm{~min}, 95^{\circ} \mathrm{C}$ for $10 \mathrm{~s}, 40$ cycles of: $95^{\circ} \mathrm{C}$ for $15 \mathrm{~s}, 58^{\circ} \mathrm{C}$ for $20 \mathrm{~s}, 72{ }^{\circ} \mathrm{C}$ for $30 \mathrm{~s}$, followed by $95^{\circ} \mathrm{C}$ for $15 \mathrm{~s}, 60^{\circ} \mathrm{C}$ for $15 \mathrm{~s}$, and $95{ }^{\circ} \mathrm{C}$ for $15 \mathrm{~s}$. Three replications for each sample were used for qPCR analyses. Analysis of variance (ANOVA) was used to test the significance of expression level.

\section{Phylogenetic analysis}

Multiple alignments of conceptual amino acid sequences were generated by using Clustal W (1.81) (http://www.cmbi.kun.nl/bioinf/ tools) with a gap open penalty of 10.00 and a gap extension penalty of 0.05 . Phylogenetic analyses were conducted using the neighborjoining method as implemented by the PHYLIP program package. BLOSUM 30 protein weight matrix was used to generate distance. Bootstrap analysis (1000 replicates) was performed to assess the support of individual branches.

\section{Results}

ADNA fragment of $332 \mathrm{bp}$, which was the expected size, was amplified from SunUp using the degenerate primers designed from $L C Y-B$ orthologs (Table 1). When the primer sequences were excluded, the fragment length was 281 bp. The sequence was submitted to GenBank (Accession No. AY753202). A papaya genomic clone obtained from GenBank (Accession No. CG026994) with a size of 818 bp from cv. SunUp submitted by TIGR showed homology with papaya $L C Y-B$.

A pair of sequence-specific primers designed from the TIGR sequences was used to screen the superpools of papaya BAC library (see Materials and Methods). Targeted fragments that contained the clone of interest were amplified from superpools SP3, SP4, SP5, SP6, and SP8. Amplified fragments from SP3 and SP6 showing the most robust band were selected for targeted amplification of matrix pools and resulted in the identification of two positive BAC clones, 32N04 and 68A06. Southern hybridization of the targeted fragment yielded six positive BACs, including 68A06. Direct amplification of BAC DNA confirmed that BAC $68 \mathrm{~A} 06$ contained the gene of interest. The insert size of BAC clone $68 \mathrm{~A} 06$ was estimated, through CHEF gel analysis, to be approximately $70 \mathrm{~kb}$ in size.

Papaya hermaphrodite and female flower cDNA libraries were also screened using the DNA fragment amplified by primers TIGR994A and TIGR994B by Southern hybridization. This procedure resulted in the identification

Figure 2 (A) Phylogenic relationship of $L C Y-B$ orthologs. Bootstrap analysis (1000 replicates) was performed to assess the support of each branch. Bootstrap values (percentages) are shown on branches when over 50. Branch lengths are proportional to the number of amino acid substitutions. GenBank accession numbers for the sequences are: citrus LCY-E (BAD07293); Arabidopsis LCY-E (NP200513); tomato LCY-E (CAA74745); cyanobacteria CRTL (NP896821); Arabidopsis LCY-B (NP187634); tomato LCY-B (CAA60170); papaya LCY-B (AAV28693); citrus LCY-B (AAF44700); pepper CCS (Q42435); and tomato CYC-B (AF254793). (B) Sequence comparison of LCY-B proteins. GenBank accession numbers for the sequences are: papaya LCY-B (DQ415894); citrus LCY-B (AAF44700); Arabidopsis LCY-B (NP187634); tomato LCY-B (CAA60170); tobacco LCY-B (S66349); rice LCY-B (XP464409); corn LCY-B (AAO18661). 
A

B

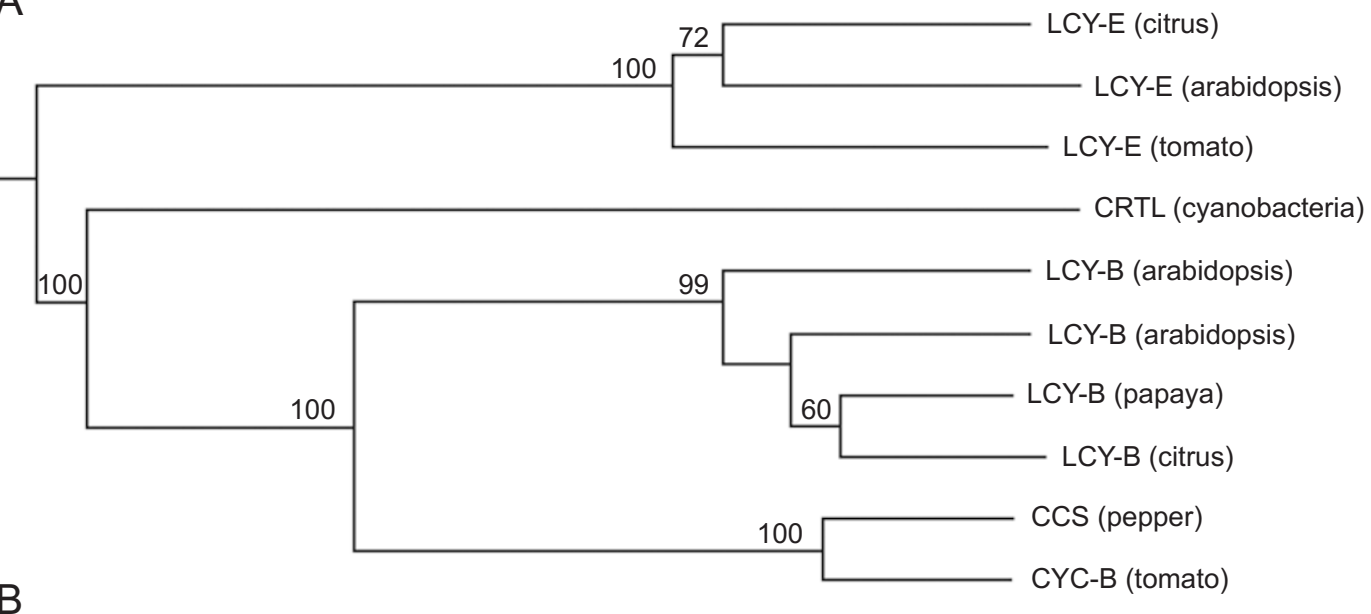

papaya

citrus

arabidopsis

tomato

tobacco

rice
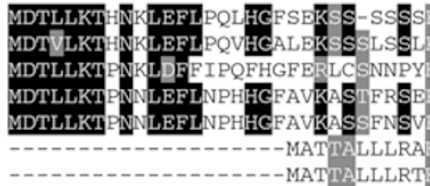

LQNPELRFETKKYWKRERDGC

corn

30 DPSKG VVDLAVVGGGPAGLAVAQQVSAGLSVCSIDPSPKLIWPNNYGVWVDEFEAMDLLDCLDTTWSGAVVYIDDK-

81 DPSKG VVDLAVVGGGPAGLAVAQQVSEAGLSVCSIDPSPKLIWPNNYGVWVDEFEAMDLLDCLDTTWSGAVVHIDDD-

6 DISKSOVVDLAIVGGGPAGLAVAQQVSEAGLSVCSIDPSPKLIWPNNYGVWVDEFEAMDLLDCLDTTWSGAVVYVDB

7 DPSKGVVVDLAVVGGGPAGLAVAQQVSEAGLSVCSIDPNPKLIWPNNYGVWVDEFEAMDLLDCLDATWSGAAVYIDDN -

7 DPSKG VVDLAVVGGGPAGLAVAQQVSEAGLSVVSIDPSPKLIWPNNYGVWVDEFEAMDLLDCLDATWSGVVVYIDDN-

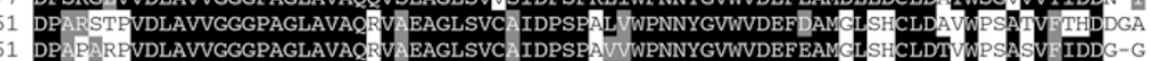

cor

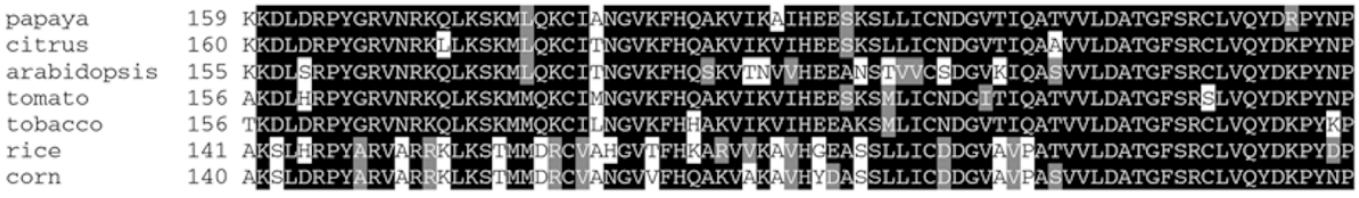

corn

papaya
citrus
arabidopsis
tomato
tobacco
rice
corn

239 GYQVAYGILAEVEKHPFDVNKMVFMDWRDSHLNSNI ELKERNSRIPTFLYAMPFSSNRIFLEETSLVARPGLRM IDIQEF

235 GYQVAYGIVAEVDCHPFDVDKMVFMDWRDKHLDSYPELKERNSK I PTFLYAMPFSSNRIFLEETSLVARPGLRM DIQER

36 GYQVAYGILABVEEHPFDVNKMVFMWRDSHLKNN WLKERNSRI PTFLYAMPFSSNRIFLEETSLVARPGLR DDIQER

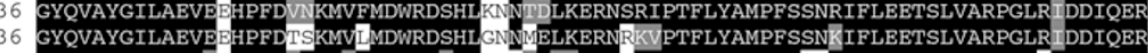

1 GYQVAYGILAEVDGHPFDIDKML FMDWRDAHLPEGSEIRERNRRIPTFLYAMPF SPTRIFLEETSLVARPGLAMDDIQER

corn 220 GYVAYGILAEVDAHPFDIDKM FMDWRDSHL PEGSEIRERNRIPTFLYAMPFS PRIFLEETSLVARPGLAMDDIQER
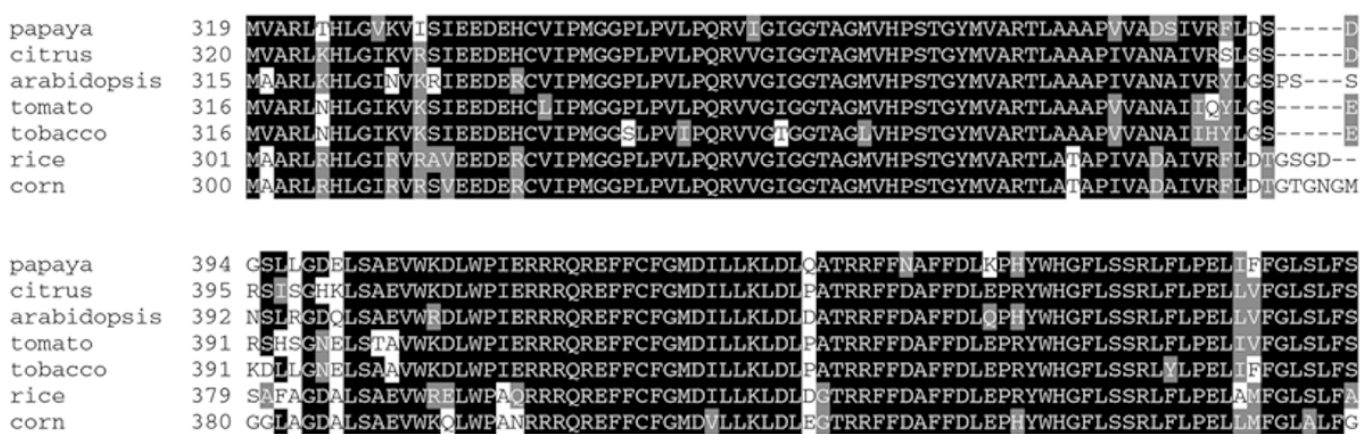

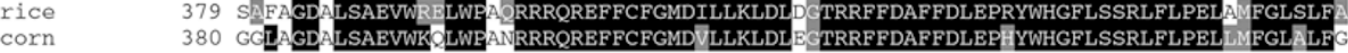

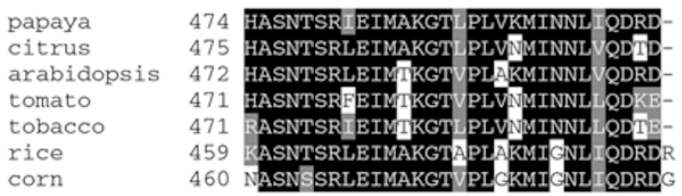


of a positive cDNA clone. This clone was sequenced and the obtained sequence was confirmed to be the papaya gene coding for lycopene $\beta$-cyclase, named $c p L C Y$ - $B$, through BLAST search at GenBank database. The total length of the cDNA sequence is $1731 \mathrm{bp}$, including 102 bp 5' untranslated region (UTR) and 342 bp 3' UTR. To obtain the complete genomic sequence of $c p L C Y-B$, direct sequencing of positive BAC clone 68A06 through primer walking started from primers designed from the TIGR sequence. The total genomic sequence from BAC 68A06 of red-fleshed genotype SunUp reached $4118 \mathrm{bp}$, including $1281 \mathrm{bp}$ of coding sequence, $2311 \mathrm{bp}$ of upstream, and 526 bp of downstream sequences (GenBank Accession No. DQ415894). The full promoter region was likely covered in the $2311 \mathrm{bp}$ upstream sequence. Two possible sites of the cpLCY-B promoter were predicted using RegSite Plant DB (www.softberry.com). The first predicted promoter site is located at -471 upstream of the start code and its related TATA box is at -506 upstream of the start code. The second predicted promoter is located at -896 upstream of the start codon and its related TATA box is at -925 upstream of the start codon. An almost equal length of genomic sequence was obtained from the yellow-fleshed genotype Kapoho. No sequence difference was detected between these two genotypes.

The cDNA sequence showed an $85 \%$ sequence identity to orthologs of citrus species and an $81 \%$ identity to $L y$ copersicon esculentum mRNA $L C Y-B$. At the amino acid level, $c p L C Y-B$ shared $80 \%$ identity with citrus $L C Y-B$, $78 \%$ identity with tomato $L C Y-B$, and $54 \%$ identity with
A

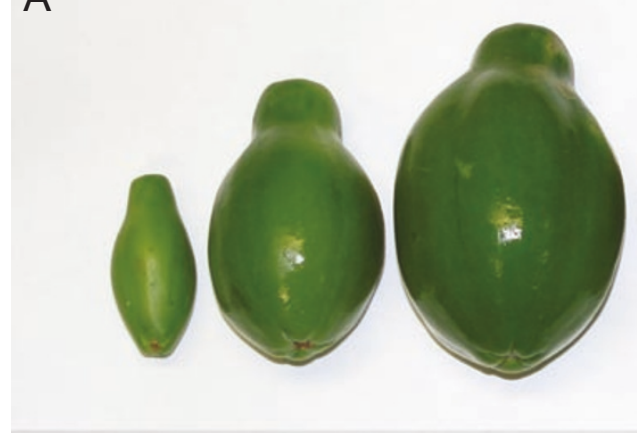

B

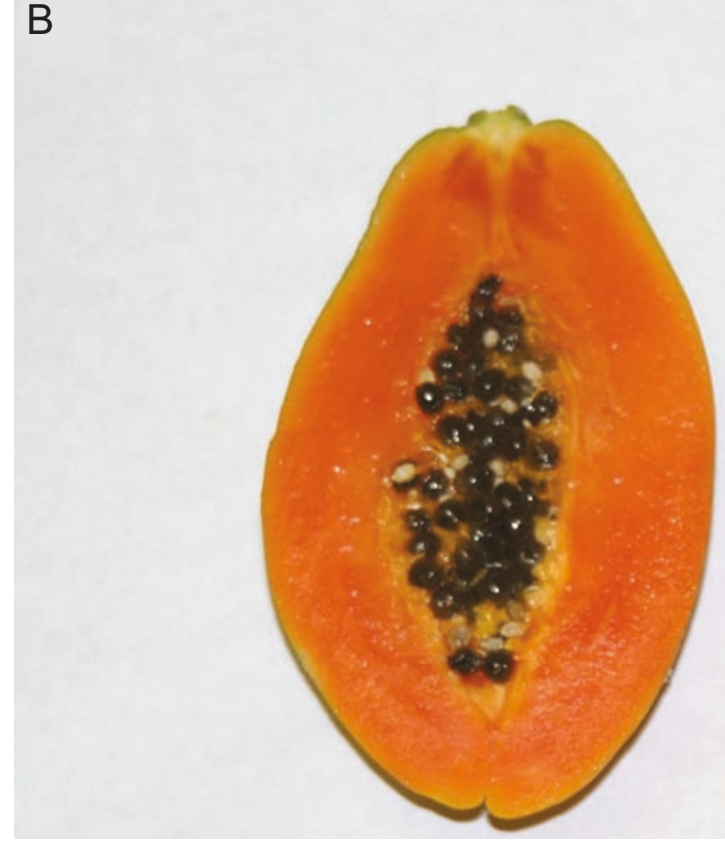

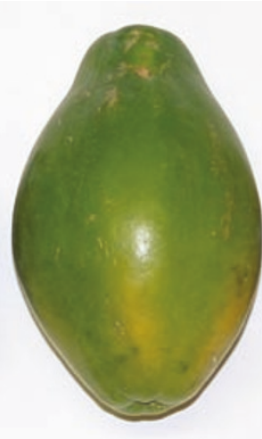
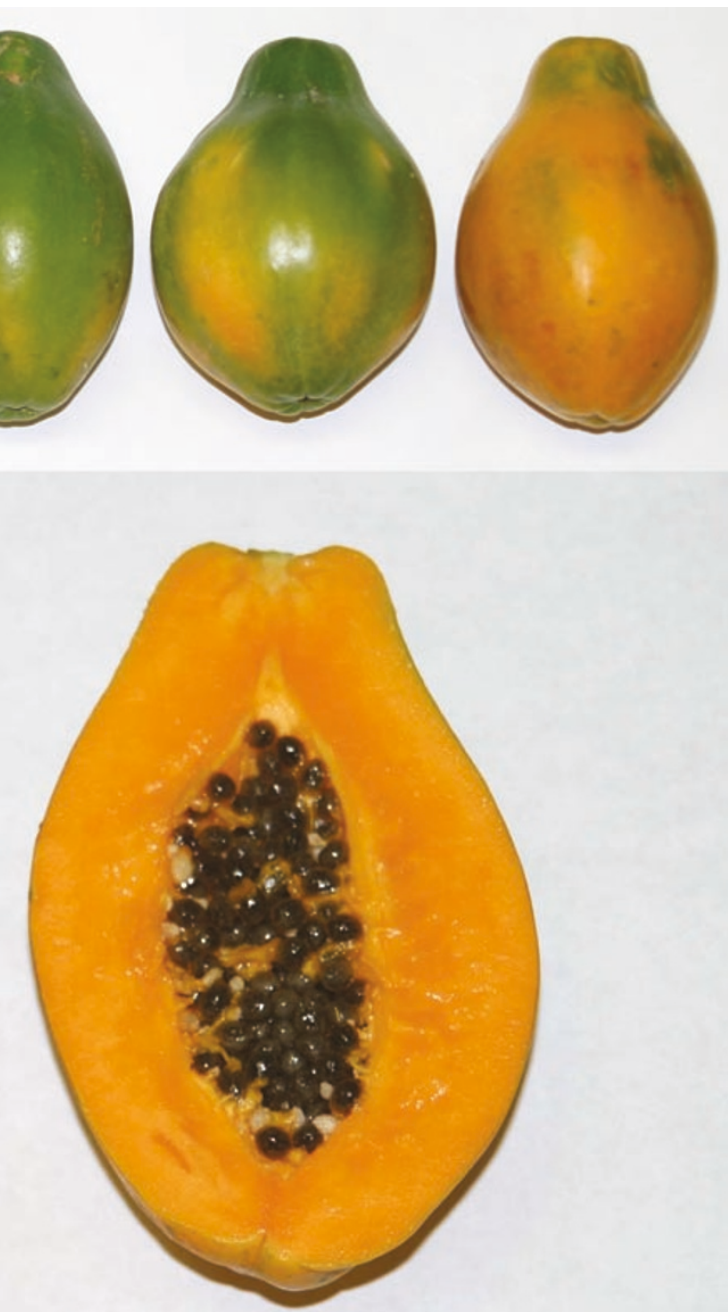

Figure 3 (A) Papaya fruits at six developmental stages used for qPCR analysis from cultivars: SunUp and Kapoho. (B) Flesh color of SunUp (red) and Kapoho (yellow). 
tomato $C Y C-B$. Phylogenetic analysis also confirmed that $c p L C Y-B$ was most closely related to citrus $L C Y-B$ and then tomato $L C Y-B$ (Figure 2).

qPCR was conducted using fruit samples from both SunUp and Kapoho immature fruit at three different sizes and three ripening stages at color break, $30 \%$, and $90 \%$ ripening stages with three replications (Figure 3). The papaya endogenous actin gene was used as a control. The expression of $c p L C Y-B$ was at the same level between the yellow- and red-fleshed genotypes and among all fruit developing and ripening stages as indicated by ANOVA (Figure 4).

Further expression analyses of $c p L C Y-B$ by qPCR using papaya leaves, flowers, and six different ripening stages of fruit tissues revealed significant differences among leaves, flowers, and fruits $\left(P=5 \times 10^{-10}\right)$. The expression of $c p L C Y$ $B$ in leaves and flowers was seven- and three-fold higher, respectively, than in fruits (Figure 4).

The degenerate primers for the $C Y C-B$ gene did not yield any PCR products using papaya genomic DNA as a template. Different DNA concentrations and annealing temperatures were tested without success, whereas the positive control of tomato genomic DNA was amplified in every test (data not shown).

\section{Discussion}

Our attempt to identify and isolate the gene controlling papaya fruit flesh color led to the cloning of the $c p L C Y-B$ gene. The isolated cDNA clone of $c p L C Y-B$ confirmed that this gene is active on the carotenoid biosynthesis pathway in papaya. The robust expression of $c p L C Y-B$ in leaves may reflect the activities of this gene in converting

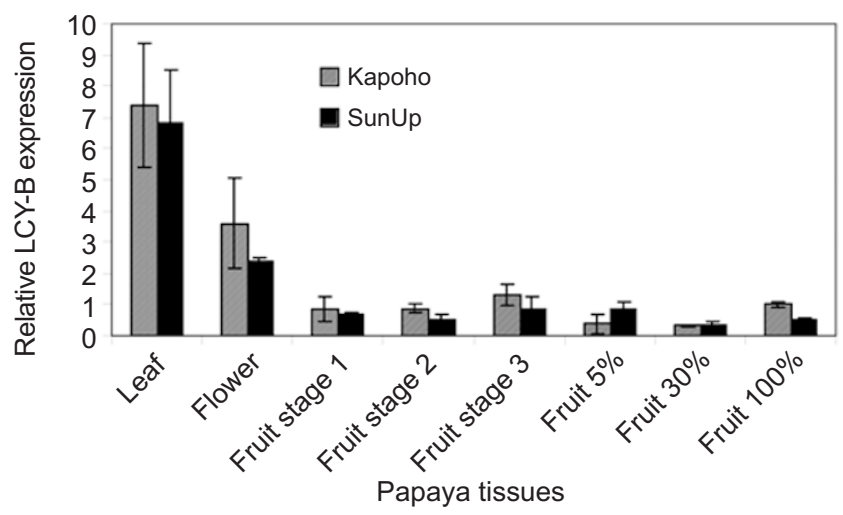

Figure 4 qPCR analyses of LCY-B expression in leaves, flowers, and six developmental stages of papaya fruit. Actin gene was used as positive control. $\delta$-carotene to $\alpha$-carotene in chloroplast [8]. Since both yellow-fleshed Kapoho and red-fleshed SunUp have white flowers without carotenoid deposition in the petal chromoplast, the high level of $c p L C Y-B$ expression is likely from enzyme activities converting $\delta$-carotene to $\alpha$-carotene in the remaining chloroplasts of the cells. The constant low level of $c p L C Y-B$ expression during the ripening process of papaya fruit suggested that this gene was down-regulated at this developmental stage, similar to the situation with the tomato $L C Y-B$ ortholog [12].

The identical full-length genomic DNA sequence of the papaya $L C Y-B$ gene, including its promoter region from both yellow- and red-fleshed genotypes Kapoho and SunUp, ruled out the possibility that $c p L C Y-B$ was the target gene responsible for the flesh color difference among different genotypes. Additional evidence to support this possibility were the similar expression levels of $c p L C Y-B$ at six maturing stages of papaya fruits from both yellow- and red-fleshed cultivars as detected by RT-PCR and qPCR analyses. The complete conversion of lycopene to carotenoids in yellow-fleshed papaya and the partial conversion of lycopene to carotenoids in red-fleshed papaya indicated an alternative pathway for converting lycopene to $\beta$-carotene as has been noted in tomato $[5,26]$. The $c p L C Y$ $B$ is likely responsible for converting part of the lycopene to $\beta$-carotene in red-fleshed fruit and also contributing to the complete degradation of lycopene in yellow-fleshed fruit. The elusive target gene in yellow-fleshed papaya fruit, accounting for converting about most of the lycopene to $\beta$-carotene, could be either a second $L C Y-B$ gene as in tomato or a novel gene as $\mathrm{Or}$ in cauliflower encoding a non-carotenogenic enzyme that regulates the accumulation of carotenoids giving the orange color [26, 31].

To test for the existence of an alternative pathway $\beta$ carotene formation in papaya, we employed the approach of Ronen et al. [26] for using degenerate primers to clone potential orthologs of the $C Y C-B$ gene in tomato. However, no papaya DNA fragment was amplified by the degenerate primers designed from orthologous sequences of five species. A single locus associated with fruit flesh color was previously mapped on linkage group 7 of a high-density map of papaya [32]. Currently, two F2 populations segregating for flesh color were planted at the Kunia Station, Oahu, for map-based cloning of this target gene that one of its alleles causes the accumulation of lycopene in redfleshed papaya fruit.

The Beta mutant in tomato has the phenotype of orange fruit due to the accumulation of $\beta$-carotene at the expense of lycopene. This $B$ locus encodes $C Y C-B$ that has identical sequence in the coding region, but different short sequence elements in the promoter region between the mutant and the wild type $[8,26]$. Extensive upstream sequence of the 
$c p L C Y-B$ gene was obtained likely including the promoter region. No DNA sequence variation was found between yellow-fleshed genotype Kapoho and red-fleshed SunUp. The absence of differences in gene expression level among genotypes and six maturing stages discounts this gene from being the causal agent of the flesh color phenotype.

The molecular bases of fruit flesh color difference in tomato, bell pepper, and onion have been elucidated through cloning and characterization of major genes in the carotenoid and flavonoid pathways. To further characterize the carotenoid biosynthetic pathway in papaya, it will be necessary to use a number of approaches including cloning orthologs of lycopene $\varepsilon$-cyclase (LCY-E) and CCS, map-based cloning of the target gene, and examining the expression pattern of these genes in leaves, flowers, and different ripening stages of fruit. These genes are likely up-regulated or down-regulated in different tissues and at different developmental stages as demonstrated in tomato $[12,26,33]$. Moreover, the efficiency of accumulating or degrading $\zeta$-carotene could affect the lycopene metabolism in yellow and red fruits. Therefore, it might be necessary to clone the phytoene desaturase and $\zeta$-carotene desaturase and test their expression levels in yellow and red genotypes to determine whether the activities of these two enzymes are the same in both genotypes.

$c p L C Y-B$ showed highest sequence homology with citrus $L C Y-B$, even though papaya is phylogenetically closer to Arabidopsis. A similar situation was found in $P F L$, a papaya $L F Y$ ortholog [34] that was more closely related to sycamore than to Arabidopsis. The different rates of divergence among functional genes might result from variable selection pressure on particular traits relevant to their roles contributing to the fitness of the species.

Fruit flesh color is often a targeted trait for papaya improvement because this trait is linked to shelf-life and nutritional value. Red-fleshed papaya is preferred by some consumers, but it is associated with a faster rate of softening, thus a shorter shelf-life. While higher content of pro-vitamin A carotenoids is a direct consequence of carotenoid metabolism in the fruit cells, the different composition of carotenoids in chromoplasts of fruit cells would have no relevance to the rate of cell wall degradation causing softening of the fruit. The red flesh and short shelf-life are most likely controlled by linked genes and the linkage might be overcome by selection in sufficiently large segregating populations.

\section{Acknowledgments}

We thank Joann Rabanal, Roxanne Quindara, Peizhu Guan, and Jim Carr for technical assistance, Henrik Albert for helpful discussion, and Ming-Li Wang and Marisa Wall for reviewing the manuscript. This work was supported in part by a USDA-ARS Cooperative Agreement (CA 58-3020-8-134) with the Hawaii Agriculture Research Center.

\section{References}

1 Krinsky NI, Wang X-D, Tang T, Russell RM. Cleavage of $\beta$ carotene to retinoids. In: Livrea MA, Vidali G, eds. Retinoids: basic science and clinical applications. Basel: Birkhaeuser, 1983: 21-28.

2 Chandrika UG, Jansz ER, Wickramasinghe SMDN, Warnasuriya ND. Carotenoids in yellow- and red-fleshed papaya (Carica papaya L.). J Sci Food Agric 2003; 83:1279-1282.

3 Hofmeyr JDJ. Genetical studies of Carica papaya L. I. The inheritance and relation of sex and certain plant characteristics. II. Sex reversal and sex forms. S Afr Dept Agric Sci Bull 1938; 187.

4 Storey WB. Papaya. In: Ferwerda FP, Wit F, Veenman H and Zoen NV, eds. Outlines of perennial crop breeding in the tropics. The Netherlands: Wageningen, 1969:389-408.

5 Karrer P, Jucker E. Carotenoids. New York, NY: Elsevier Publishing Co., 1950.

6 Yamamoto H. Differences in carotenoid composition between red- and yellow-fleshed papaya. Nature 1964; 201:1049-1050.

7 Fraser PD, Truesdale MR, Bird CR, Schuch W, Bramley PM. Carotenoid biosynthesis during tomato fruit development. Plant Physiol 1994; 105:405-413.

8 Hirschberg J. Carotenoid biosynthesis in flowering plants. Curr Opin Plant Biol 2001; 4:210-218.

9 Goodwin TW. The Biochemistry of Carotenoids. 2nd Edition, vol 1. London: Chapman \& Hall, 1980.

10 Barber NJ and Barber J. Lycopene and prostate cancer. Prostate Cancer Prostatic Dis 2002; 5:6-13.

11 Stahl W, Seis H. Uptake of lycopene and its geometrical isomers is greater from heat processed than unprocessed tomato juice. J Nutr 1992; 122:265-277.

12 Pecker I, Gabbay R, Cunningham Jr FX, Hirschberg J. Cloning and characterization of the cDNA for lycopene beta-cyclase from tomato reveals decrease in its expression during fruit ripening. Plant Mol Biol 1996; 30:807-819.

13 Koyama Y. Structures and functions of carotenoids in photosynthetic systems. J Photochem Photobiol B 1991; 9:256-280.

14 Frank H, Cogdell RJ. Photochemistry and function of carptenoids in photosynthesis. In: Young AJ, Britton G, eds. Carotenoids and Photosynthesis. London: Chapman \& Hall, 1993:253-326.

15 Cunningham Jr, FX, Gantt E. Genes and enzymes of carotenoid biosynthesis in plants. Annu Rev Plant Physiol Plant Mol Biol 1998; 49:557-583.

16 Britton G. Later reactions of carotenoid biosynthesis. Pure Appl Chem 1976; 223-236.

17 Britton G. Carotenoid biosynthesis - a target for herbicide activity. Z Naturforsch C 1979; 34:979-985.

18 Cunningham Jr FX, Pogson B, Sun Z, et al. Functional analysis of the $\beta$ and $\varepsilon$ lycopene cyclase enzymes of Arabidopsis reveals a mechanism for control of cyclic carotenoid formation. Plant Cell 1996; 8:1613-1626.

19 Tian L, Magallanes-Lundback M, Musetti V, DellaPenna D. 
Functional analysis of $\beta$ - and $\varepsilon$-ring carotenoid hydroxylases in arabidopsis. Plant Cell 2003; 15:1320-1332.

20 Tian L, DellaPenna D. Progress in understanding the origin and functions of carotenoid hydroxylases in plants. Arch Biochem Biophys 2004; 430:22-29.

21 Bouvier F, Huguency P, d'Harlingue A, Kuntz M, Camara B. Xanthophyll biosynthesis in chromoplasts: isolation and molecular cloning of an enzyme catalyzing the conversion of 5,6epoxycarotenoid into ketocarotenoid. Plant J 1994; 6:45-54.

22 Hirschberg J, Cohen M, Harker M, et al. Molecular genetics of the carotenoid biosynthesis pathway in plants and algae. Pure Appl Chem 1997; 69:2151-2158.

23 Issacson T, Ronen G, Zamir D, Hirschberg J. Cloning of tangerine from tomato reveals a carotenoid isomerase essential for the production of $\beta$-carotene and xanthophylls in plants. Plant Cell 2002; 14:333-342.

24 Huguency P, Badillo A, Chen HC, et al. Metabolism of cyclic carotenoids: a model for the alteration of this biosynthetic pathway in Capsicum annuum chromoplasts. Plant J 1995; 8:417-424.

25 Bouvier F, d'Harlingue A, Camara B. Molecular analysis of carotenoid cyclase inhibition. Arch Biochem Biophys 1997; 346:53-64.

26 Ronen G, Carmel-Goren L, Zamir D, Hirschberg J. An alternative pathway to $\beta$-carotene formation in plant chromoplasts discovered by map-based cloning of Beta and old-gold color mutations in tomato. Proc Natl Acad Sci USA 2000; 97:11102-11107.

27 Bouvier F, d'Harlingue A, Backhaus RA, Kumagai MH, Camara
B. Identification of neoxanthin synthase as a carotenoid cyclase paralog. Eur J Biochem 2000; 267:6346-6352.

28 Manshardt RM. "UH Rainbow” papaya. Germplasm, G-1. Honolulu, HI: University of Hawaii College of Tropical Agriculture and Human Resources, 1998.

29 Ming R, Moore PH, Zee F, et al. Construction and characterization of a papaya BAC library as a foundation for molecular dissection of a tree-fruit genome. Theor Appl Genet 2001; 102:892-899.

30 Tai TH, Tanksley SD. A rapid and inexpensive method for isolation of total DNA from dehydrated plant tissue. Plant Mol Biol Rep 1990; 8:297-303.

$3131 \mathrm{Lu} \mathrm{S}$, O'Halloran DM, Cosman K, et al. Or, a plastid protein, accounts for the high level accumulation of beta-carotene in cauliflower. Amn Soc Plant Biol Ann Meet 2005; 606.

$32 \mathrm{Ma} \mathrm{H}$, Moore PH, Liu Z, et al. High-density linkage mapping revealed suppression of recombination at the sex determination locus in papaya. Genetics 2004; 166:419-436.

33 Ronen G, Cohen M, Zamir D, Hirschberg J. Regulation of carotenoid biosynthesis during tomato fruit development: expression of the gene for lycopene epsilon-cyclase is down-regulated during ripening and is elevated in the mutant Delta. Plant J 1999; 17:341-351.

34 Yu Q, Moore PH, Albert HH, Roader AHK, Ming R. Cloning and characterization of a FLORICAULA/LEAFY ortholog, PFL, in polygamous papaya. Cell Res 2005; 15:576-584.

Edited by Lu Liang 